\title{
PENDUGAAN KEDALAMAN AIR TANAH MENGGUNAKAN METODE GEOLISTRIK KONFIGURASI SCHLUMBERGER DI DESA BOJONGSARI KECAMATAN ALIAN KABUPATEN KEBUMEN
}

\author{
Sehah $^{1^{*}}$, Abdullah Nur Aziz ${ }^{2 * *}$ \\ ${ }^{1}$ Jurusan Fisika, Fakultas MIPA Universitas Jenderal Soedirman, Karangwangkal Purwokerto \\ ${ }^{2}$ Laboratorium Elektronika, Instrumentasi, dan Geofisika FakultasMIPA \\ Universitas Jenderal Soedirman Purwokerto \\ *E-Mail: abdnuraziz@gmail.com **E-Mail: sehah.geophysics@gmail.com
}

\begin{abstract}
ABSTRAK
Pendugaan kedalaman air tanah di Desa Bojongsari, Kecamatan Alian, Kabupaten Kebumen menggunakan metode Geolistrik konfigurasi Schlumberger telah dilaksanakan pada tanggal 9 Oktober 2015. Pengukuran geolistrik telah dilakukan di tiga titik lokasi yaitu Bojongsari 01, Bojongsari 02, dan Bojongsari 03. Pengolahan data dan pemodelan dilakukan hingga diperoleh data resistivitas yang merepresentasikan jenis batuan bawah permukaan. Untuk titik Bojongsari 01 lapisan akuifer dangkal diperkirakan tersusun atas pasir berbutir halus $(0,85 \Omega \mathrm{m})$ dan lempung pasiran $(13,25 \Omega \mathrm{m})$ dengan kedalaman 7,35-29,44 $\mathrm{m}$, adapun lapisan akuifer dalam tersusun atas pasir berbutir halus $(0,44 \Omega \mathrm{m})$ dengan kedalaman 33,72-85,76 m. Untuk titik Bojongsari 02 lapisan akuifer dangkal diperkirakan tersusun atas lempung pasiran $(19,43 \Omega \mathrm{m})$ dan pasir lempungan $(3,18$ $\Omega \mathrm{m}$ ) dengan kedalaman 7,61-43,32 m, adapun lapisan akuifer dalam tersusun atas pasir lempungan $(5,97 \Omega \mathrm{m})$ dengan kedalaman $53,94 \mathrm{~m}$. Untuk titik Bojongsari 03 lapisan akuifer dangkal diperkirakan tersusun atas pasir berbutir halus $(1,18 \Omega \mathrm{m})$ dengan kedalaman 11,28-38,25 m, sedangkan lapisan akuifer dalam tersusun atas lempung pasiran berbutir kasar $(28,02 \Omega \mathrm{m})$ dengan kedalaman 77,25 m. Berdasarkan hasil pemodelan di atas, lapisan akuifer yang diperkirakan paling cocok dimanfaatkan untuk proyek pengadaan air bersih di Desa Bojongsari adalah lapisan akuifer air tanah dalam pada titik Bojongsari 01.
\end{abstract}

Kata Kunci: Akuifer Air Tanah; Geolistrik; Konfigurasi Schlumberger; Desa Bojongsari.

\begin{abstract}
Estimation of the depth of the groundwater was executed in Bojongsari village, District of Alian, Region of Kebumen using Geoelectric method with Schlumberger configuration. It was measured at three locations included Bojongsari 01, Bojongsari 02, and Bojongsari 03. The data processing and modeling were obtained the resistivity data representing the type of sub-surface rocks. At Bojongsari 01, the shallow groundwater aquifer was expected composed of fine grained sand $(0.85$ $\Omega \mathrm{m})$ and sandy clay $(13.25 \Omega \mathrm{m})$ at the depth of 7.35 to 29.44 meters, while the deep aquifer was composed of fine grained sand $(0.44 \Omega \mathrm{m})$ at the depth of 33.72 to 85.76 meters. At Bojongsari 02 , the shallow aquifer was estimated composed of sandy clay $(19.43 \Omega \mathrm{m})$ and silty sand $(3.18 \Omega \mathrm{m})$ at the depth of 7.61 to 43.32 meters, while the deep aquifer was composed of silty sand $(5.97 \Omega \mathrm{m})$ at a depth of 53.94 meters. At Bojongsari 03, the shallow aquifer was estimated composed of fine grained sand $(1.18 \Omega \mathrm{m})$ at the depth of 11.28 to 38.25 meters, while the deep aquifer was composed of coarse grained sandy clay $(28.02 \Omega \mathrm{m})$ with depth 77.25 meters. Based on these results, the best estimated aquiferfor water supply projects in the Bojongsari is the deep groundwater aquifer at Bojongsari 01.
\end{abstract}

Keywords: Groundwater Aquifer; Geoelectric; Schlumberger Configuration; Village of Bojongsari. 


\section{PENDAHULUAN}

Pemerintah Indonesia mempunyai komitmen sangat kuat untuk mencapai Millenium Development Goals, dimana salah satunya adalah turunnya jumlah penduduk yang belum mempunyai akses air minum dan sanitasi dasar sebesar 50\% pada tahun 2015. Berdasarkan Undang-Undang nomor 32 tahun 2004 tentang Pemerintah Daerah dan Undang-Undang nomor 33 tahun 2004 tentang Perimbangan Keuangan Pemerintah Pusat dan Pemeritah Daerah, maka pemerintah daerah bertanggung jawab penuh untuk memberikan pelayanan dasar kepada masyarakat di daerahnya masing-masing, termasuk pelayanan air minum dan sanitasi. Proyek Penyediaan Air Minum dan Sanitasi Berbasis Masyarakat (PAMSIMAS) merupakan salah satu program dan aksi nyata dari pemerintah pusat dan pemerintah daerah dengan dukungan dana Bank Dunia untuk meningkatkan penyediaan air minum, sanitasi, dan meningkatkan derajat kesehatan masyarakat khususnya untuk menurunkan angka penyakit diare dan penyakit lainnya yang ditularkan melalui air maupun lingkungan. ${ }^{1}$ Salah satu daerah yang menjadi target PAMSIMAS adalah Desa Bojongsari, Kecamatan Alian, Kabupaten Kebumen, Jawa Tengah, dalam bentuk penyediaan sumber air bersih, karena desa ini termasuk daerah rawan kekeringan. ${ }^{2}$

Penyediaan sumber air bersih di Desa Bojongsari telah dilakukan melalui eksplorasi geofisika menggunakan metode geolistrik konfigurasi schlumberger. Akuisisi data dengan metode geolistrik dilakukan dengan cara mengalirkan arus listrik searah ke dalam lapisan batuan kerak bumi melalui dua buah elektroda arus pada titik $\mathrm{C}_{1}$ dan $\mathrm{C}_{2}$. Arus listrik yang diinjeksikan ke dalam lapisan batuan akan menyebar secara merata ke seluruh medium batuan seperti ditunjukkan pada Gambar 1. Polarisasi listrik yang terjadi di dalam batuan diukur beda potensialnya melalui dua buah elektroda potensial di titik $\mathrm{P}_{1}$ dan $\mathrm{P}_{2}$.

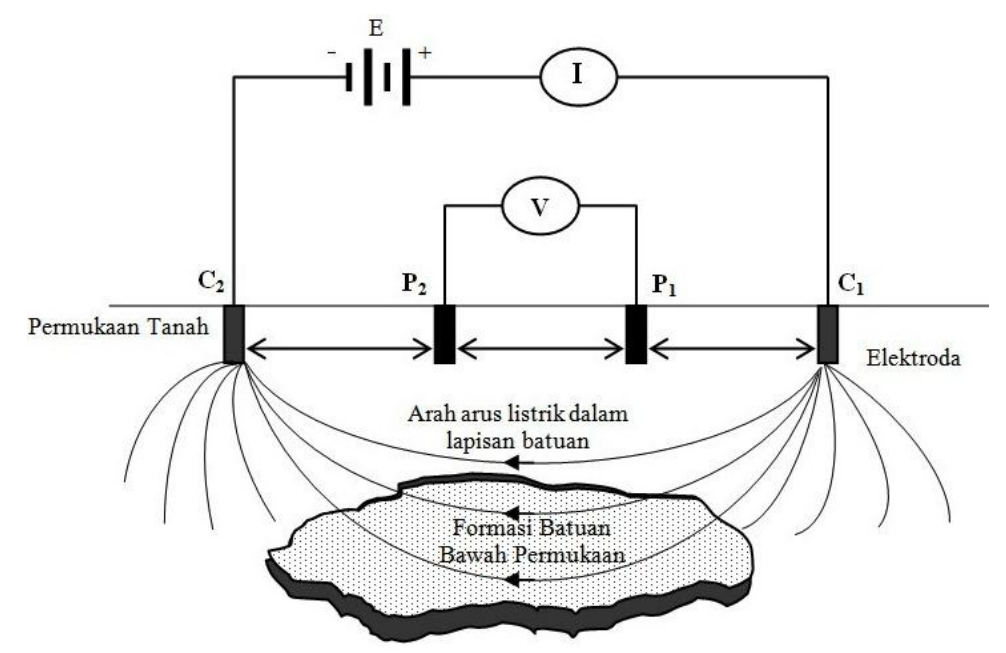

Gambar 1. Skema peralatan pengukuran metode geolistrik resistivitas.

Selanjutnya setelah diketahui nilai arus $(I)$ dan beda potensial $(\Delta V)$, maka resistivitas semu (apparent resistivity) untuk masing-masing lapisan batuan bawah permukaan dapat dihitung mengunakan persamaan ${ }^{1}$ :

$$
\rho_{a}=K \frac{\Delta V}{I}
$$


dimana $\rho_{\mathrm{a}}$ adalah resistivitas semu, $\Delta V$ adalah beda potensial, $K$ adalah faktor geometri, dan $I$ adalah kuat arus listrik. Nilai faktor geometri $(K)$ tergantung dari konfigurasi atau susunan elektroda yang digunakan dalam pengukuran geolistrik. Adapun untuk konfigurasi Schlumberger, susunan dan jarak antar elektroda didesain seperti Gambar 2 dengan nilai faktor geometri dapat dirumuskan sebagai berikut ${ }^{3}$ :

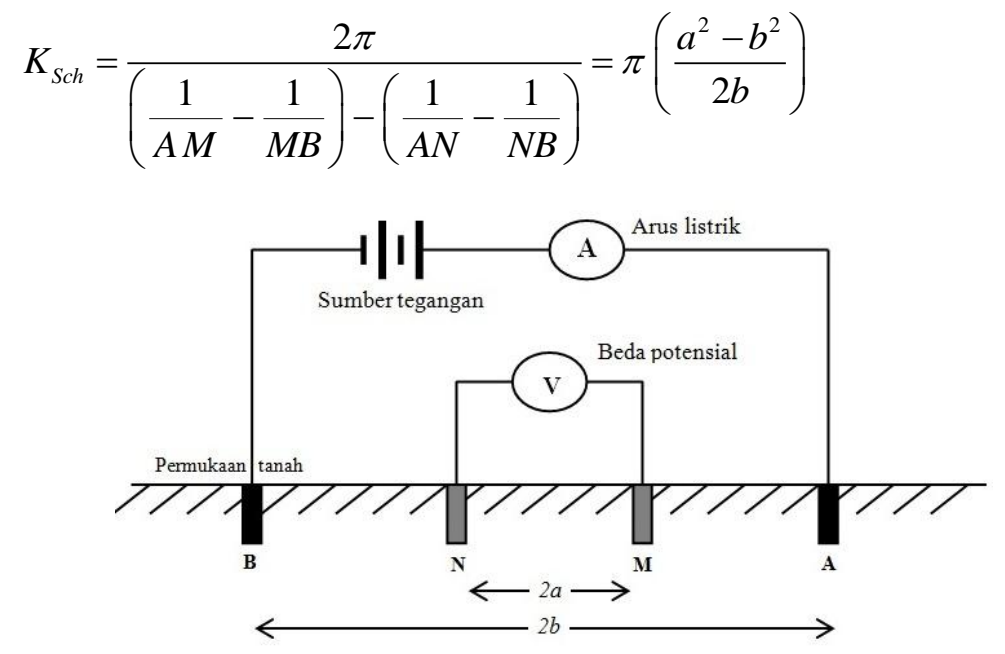

Gambar 2. Skema peralatan pengukuran teknik geolistrik dengan konfigurasi Schlumberger.

Berdasarkan data resistivitas semu batuan bawah permukaan yang didukung oleh informasi geologi, maka dilakukan pemodelan dan interpretasi struktur litologi (batuan) bawah permukaan, termasuk lapisan akuifer air tanah yang menjadi target penelitian. Hasil interpretasi digunakan untuk mengestimasi kedalaman lapisan akuifer dan menginvestigasi potensi sumber air tanah yang terkandung di dalamnya untuk proyek penyediaan sumber air bersih bagi masyarakat Desa Bojongsari. Lapisan akuifer yang ingin dimanfaatkan di dalam program PAMSIMAS adalah akuifer air tanah dalam (deep groundwater aquifer), karena umumnya volume airnya sangat banyak, kondisinya bersih, dan berasal dari zona imbuhan (recharge area) yang tidak terkontaminasi di wilayah pegunungan. Sedangkan lapisan akuifer dangkal (shallow aquifer) umumnya banyak digunakan sebagai sumber air bagi sumur-sumur warga, yang umumnya berasal dari rembesan air permukaan seperti air hujan, sungai, dan danau. ${ }^{3}$

\section{METODE PENELITIAN}

Penelitian dilaksanakan di Desa Bojongsari, Kecamatan Alian, Kabupaten Kebumen Jawa Tengah, dengan peta lokasi seperti ditunjukkan pada Gambar 3. Peralatan utama yang digunakan dalam penelitian ini adalah Resistivity meter merk NANIURA model NRD 22S dilengkapi dengan sepasang elektroda tembaga dan sepasang elektroda stainless steel, accu 12 volt, 2 buah pita ukur @ 250 meter, 2 buah kabel arus @ 300 meter, serta 2 buah kabel potensial @ 150meter. Peralatan pendukung lain adalah 2 buah Handy Talky (HT), 4 buah palu, beberapa kabel penghubung, 1 unit kendaraan pengangkut, 1 set buku catatan dan alat tulis, 1 set laptop dan printer, dan 1 paket perangkat lunak Geolistrik Progress. ${ }^{5}$ 


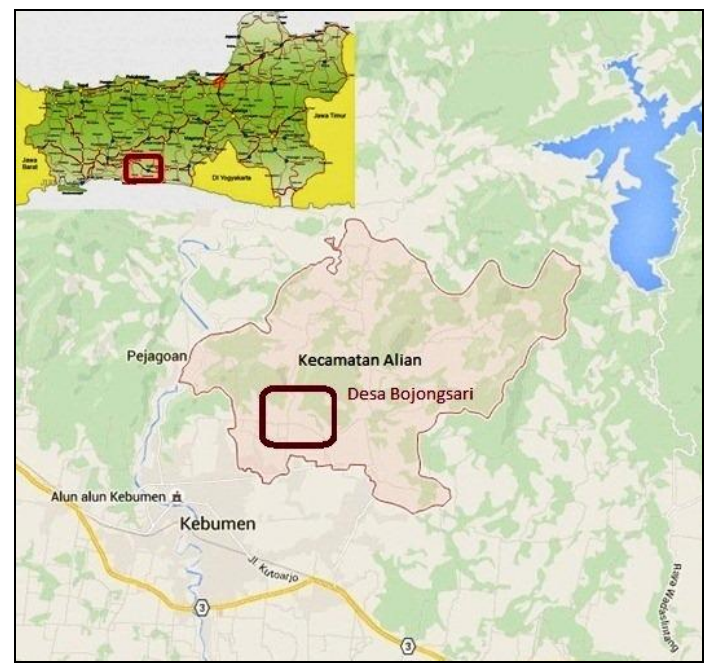

Gambar 3. Peta lokasi daerah penelitian; Desa Bojongsari, Kecamatan Alian, Kabupaten Kebumen.

Teknik pengukuran Geolistrik dengan konfigurasi Schlumberger dilakukan dengan cara memvariasi jarak elektroda $C_{1}$ terhadap $P_{1}$, serta $C_{2}$ terhadap $P_{2}$ seperti Gambar 4 . Pemvariasian jarak elektroda ini dilakukan untuk mendapatkan informasi model struktur geologi dan litologi batuan bawah permukaan berdasarkan nilai resistivitas secara vertikal. Adanya perbedaan nilai resistivitas batuan bawah permukaan, tampak sangat jelas pada saat penentuan kedalaman lapisan batuan yang mempunyai resistivitas berlainan. ${ }^{6}$ Jarak bentangan elektroda potensial $\left(\mathrm{P}_{1}\right.$ dan $\left.\mathrm{P}_{2}\right)$ dibuat berubah perlahan, sedang elektroda arus $\left(\mathrm{C}_{1}\right.$ dan $\left.\mathrm{C}_{2}\right)$ digerakkan sesuai penambahan jarak bentangan elektroda, seperti Gambar 1. Jarak bentangan elektroda arus maupun potensial mempengaruhi nilai faktor $K$. Semakin lebar jarak bentangan elektroda, maka informasi jenis litologi (batuan) bawah permukaan yang diperoleh juga semakin dalam.

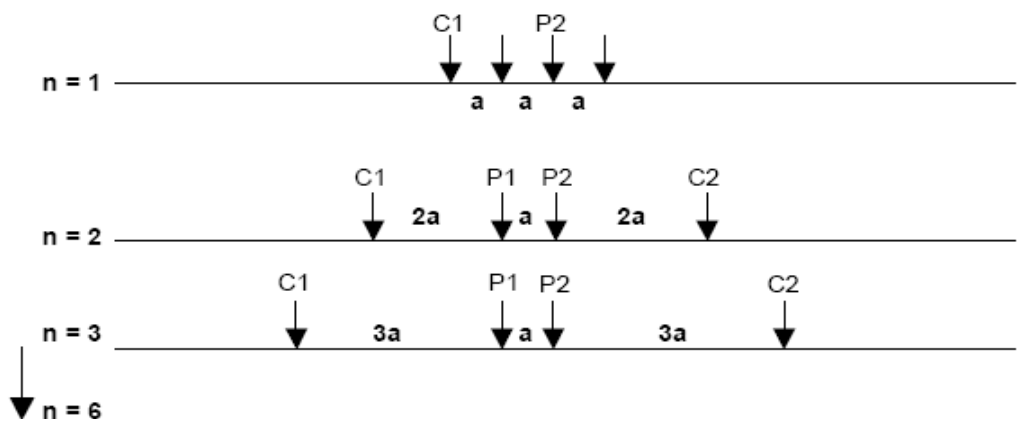

Gambar 4. Pergerakan elektroda arus dalam survei Geolistrik Tahanan Jenis dengan konfigurasi Schlumberger. ${ }^{7}$

Resistivitas batuan yang terukur seperti persamaan (1), bukan nilai resistivitas yang sebenarnya tetapi resistivitas semu (apparent resistivity). Nilai resistivitas semu tergantung dari jarak elektroda dan heterogenitas medium batuan. Hal ini menunjukkan bahwa setiap lapisan batuan di dalam kerak bumi mempunyai nilai resistivitas yang berbeda, tergantung dari beberapa parameter seperti kandungan logam, komposisi mineral, tekstur, kandungan air, temperatur, permeabilitas medium, dan umur geologi. ${ }^{8}$ Hasil pengukuran Geolistrik menggunakan konfigurasi Schlumberger menghasilkan kurva resistivitas semu $\left(\rho_{\mathrm{a}}\right)$ versus kedalaman lapisan batuan. Kurva lapangan ini digunakan sebagai dasar untuk menghitung 
nilai resistivitas sesungguhnya (true resistivity) lapisan batuan bawah permukaan melalui pemodelan. Hasil pemodelan adalah kurva resistivitas sesungguhnya versus kedalaman lapisan-lapisan batuan. Berdasarkan kurva ini,dilakukan interpretasi sehingga diperoleh model struktur litologi bawah permukaan, termasuk jenis, susunan, dan kedalaman lapisan akuifer air tanah. ${ }^{6}$

\section{HASIL DAN PEMBAHASAN}

Secara geologi, daerah penelitian tersusun oleh Formasi Aluvium yang terdiri atas lempung, lanau, pasir, kerikil, dan kerakal. Material endapan tersebut diperkirakan berasal dari Sungai Kedungbener yang melalui Desa Bojongsari dari utara ke selatan. Di bagian timur formasi Aluvium terdapat formasi Halang yang terdiri atas perselingan batu pasir, batu gamping, napal, dan tuff dengan sisipan breksi; yang dipengaruhi oleh arus turbid dan pelengseran bawah arus laut. ${ }^{9}$ Pengukuran geolistrik dengan konfigurasi Schlumberger telah dilakukan di tiga titik lokasi di Desa Bojongsari. Resistivitas semu masing-masing lapisan batuan di setiap titik lokasi dihitung berdasarkan persamaan (1). Hasil perhitungan ini dimodelkan menggunakan Geolistrik Progress 3.0, dimana hasilnya ditunjukkan pada Gambar 5 hingga Gambar 7. Adapun hasil interpretasi litologi (batuan) dan hidrogeologi (air tanah) terhadap hasil pemodelan ditunjukkan pada Tabel 1 hingga Tabel 3. Pemodelan dan interpretasi yang dilakukan terhadap data resistivitas disetiap titik lokasi disesuaikan dengan informasi geologi daerah setempat.
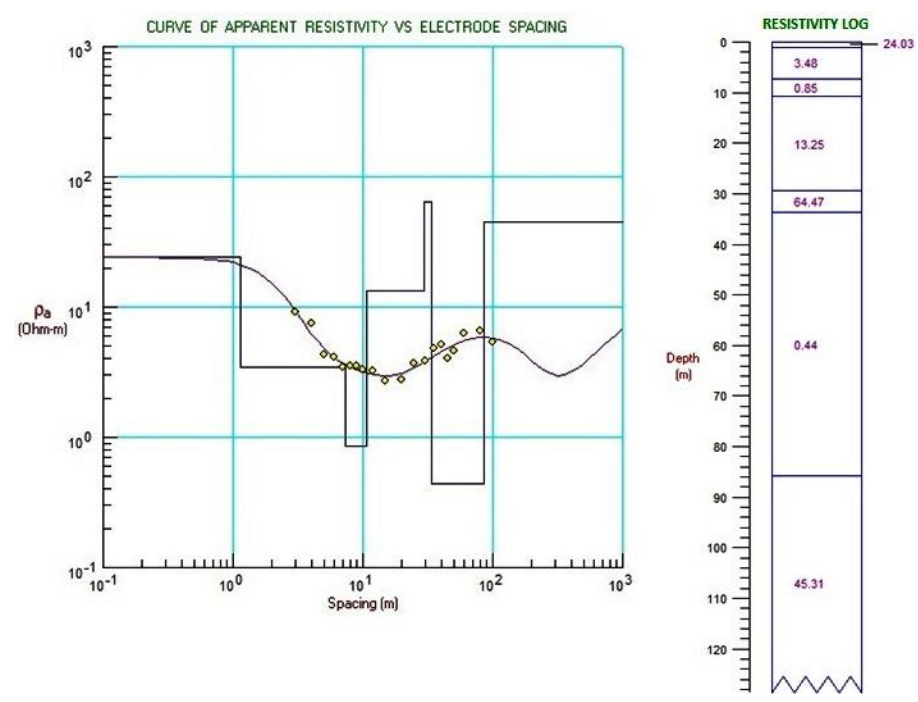

Gambar 5. Kurva dan log resistivitas batuan bawah permukaan hasil pemodelan pada titik lokasi Bojongsari 01.

Titik lokasi Bojongsari 01 terletak pada posisi geografis $07^{\circ} 40^{\prime}$ 07,637'dan $109^{\circ} 43^{\prime}$ 26,74" dengan panjang bentangan elektroda arus (1/2AB) adalah $100 \mathrm{~m}$. Berdasarkan hasil pemodelan seperti ditunjukkan pada Gambar 5, lapisan akuifer dangkal diinterpretasi terdiri atas pasir berbutir halus $(\rho=0,85 \Omega \mathrm{m})$ dengan kedalaman 7,35 - 10,78 $\mathrm{m}$ dan lempung pasiran $(\rho=13,25 \Omega m)$ dengan kedalaman 10,78 - 29,44 m. Akuifer dangkal umumnya dimanfaatkan masyarakat sebagai sumber air sumur. Adapun lapisan akuifer air tanah dalam diperkirakan tersusun atas pasir berbutir halus $(\rho=0,44 \Omega \mathrm{m})$ pada kedalaman 33,72 - 85,76 $\mathrm{m}$ dan ketebalan 52,04 m. Lapisan tersebut dibatasi oleh dua batuan kompak yang berperan 
besar sebagai lapisan penutup yang relatif kedap air, sehingga tidak terkena rembesan air dari akuifer dangkal. Lapisan batuan pertama hingga keenam diperkirakan merupakan formasi aluvium (endapan), sedangkan lapisan terakhir diperkirakan sebagai anggota formasi Halang. Hasil interpretasi batuan bawah permukaan secara lengkap dapat dilihat pada Tabel 1. Secara ekonomis, akuifer air tanah dalam pada titik lokasi Bojongsari 01 sangat prospek jika dimanfaatkan untuk penyediaan sumber air bersih pada program PAMSIMAS dalam skala besar di Desa Bojongsari. ${ }^{10}$

Tabel 1. Interpretasi hasil pemodelan data resistivitas 1D pada titik lokasi Bojongsari 01

\begin{tabular}{ccccc}
\hline \multirow{2}{*}{ No. } & Log Resisitivitas & \multirow{2}{*}{ Kedalaman $(\mathrm{m})$} & \multicolumn{2}{c}{ Interpretasi } \\
\cline { 4 - 5 } & $(\Omega \mathrm{m})$ & $0-1,15$ & Litologi & Hidrogeologi \\
\hline 1 & 24,03 & $1,15-7,35$ & Lempung & - \\
2 & 3,48 & $7,35-10,78$ & Pasir berbutir halus & Akuifer dangkal \\
3 & 0,85 & $10,78-29,44$ & Lempung pasiran & Akuifer dangkal \\
4 & 13,25 & $29,44-33,72$ & Batulempung kompak & - \\
5 & 64,47 & $33,72-85,76$ & Pasir berbutir halus & Akuifer dalam \\
6 & 0,44 & $\geq 85,76$ & Perselingan batupasir, & - \\
7 & 45,31 & & batulempung, dan tuff & \\
& & & &
\end{tabular}
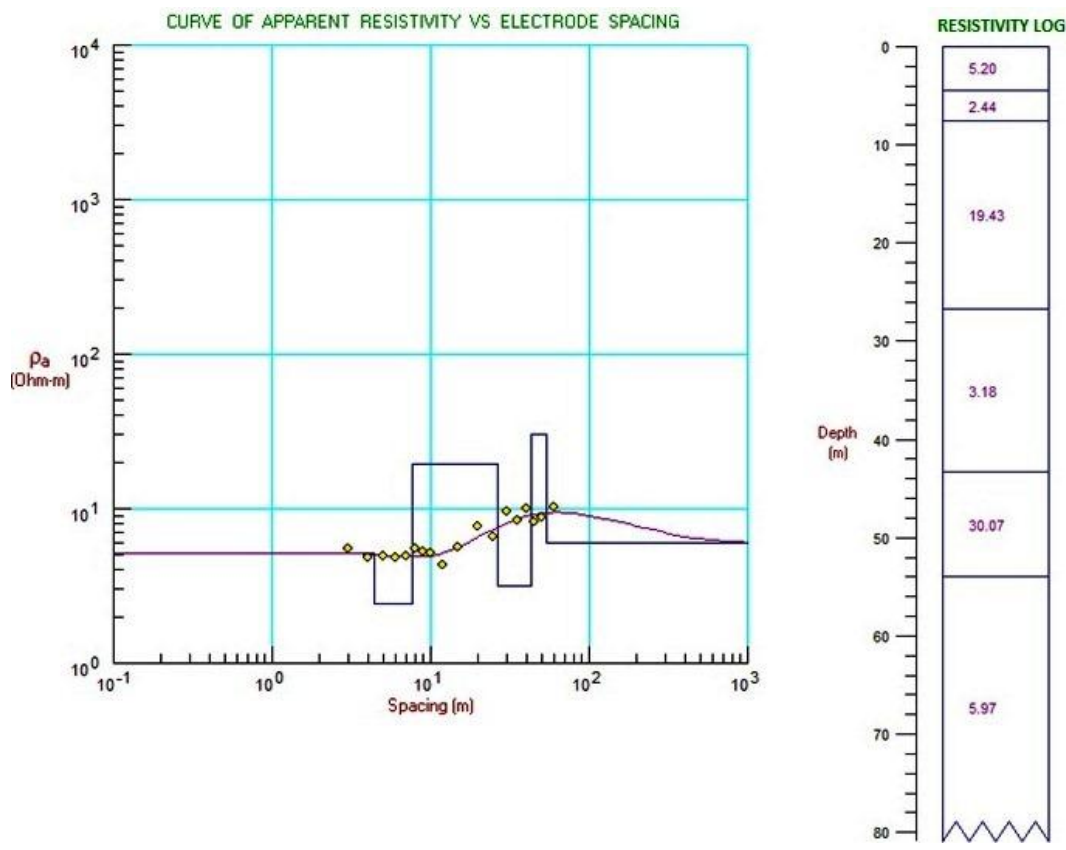

Gambar 6. Kurva dan log resistivitas batuan bawah permukaan hasil pemodelan pada titik lokasi Bojongsari 02.

Titik lokasi Bojongsari 02 terletak pada posisi geografis $07^{\circ} 40^{\prime}$ 02,034"dan $109^{\circ} 43^{\prime} 17,8^{\prime \prime}$ dengan panjang bentangan elektroda arus $(1 / 2 \mathrm{AB})$ adalah 60 meter. Berdasarkan hasil pemodelan sebagaimana terlihat pada Gambar 6, lapisan akuifer dangkal diperkirakan tersusun atas pasir lempungan $(\rho=19,43 \Omega \mathrm{m})$ dengan kedalaman 7,61 - 26,65 $\mathrm{m}$ dan pasir berbutir halus $(\rho=3,18 \Omega \mathrm{m}$ ) pada kedalaman 26,65 - 43,32 m. Adapun lapisan akuifer dalam diperkirakan tersusun atas pasir berbutir sedang $(\rho=5,97 \Omega \mathrm{m})$ dengan kedalaman 53,94 m hingga batas bawah yang tidak jelas. Kendala pengukuran geolistrik di lokasi ini adalah keterbatasan panjang bentangan elektroda arus (AB) akibat terhalang bangunan rumah 
penduduk. Akibatnya batas bawah lapisan akuifer dalam tidak dapat terinterpretasi secara jelas. Namun demikian berdasarkan nilai resistivitas batuan dan hasil interpretasi litologinya, air tanah dalam pada lapisan akuifer ini diperkirakan masih prospek untuk dimanfaatkan. ${ }^{10}$ Secara lengkap hasil interpretasi batuan bawah permukaan dapat dilihat pada Tabel 2 .

Tabel 2. Interpretasi hasil pemodelan data resistivitas 1D pada titik lokasi Bojongsari 02

\begin{tabular}{ccccc}
\hline \multirow{2}{*}{ No. } & Log Resisitivitas & \multirow{2}{*}{ Kedalaman $(\mathrm{m})$} & \multicolumn{2}{c}{ Hasil Interpretasi } \\
\cline { 4 - 5 } & $(\Omega \mathrm{m})$ & $0-4,42$ & Lanau pasiran basah & Hidrogeologi \\
\hline 1 & 5,20 & $4,42-7,61$ & Lempung & - \\
2 & 2,44 & $7,61-26,65$ & Pasir lempungan & Akuifer dangkal \\
3 & 19,43 & $26,65-43,32$ & Pasir berbutir halus & Akuifer dangkal \\
4 & 3,18 & $43,32-53,94$ & Batulempung kompak & - \\
5 & 30,07 & $\geq 53,94$ & Pasirberbutir sedang & Akuifer dalam \\
6 & 5,97 & & & \\
\hline
\end{tabular}
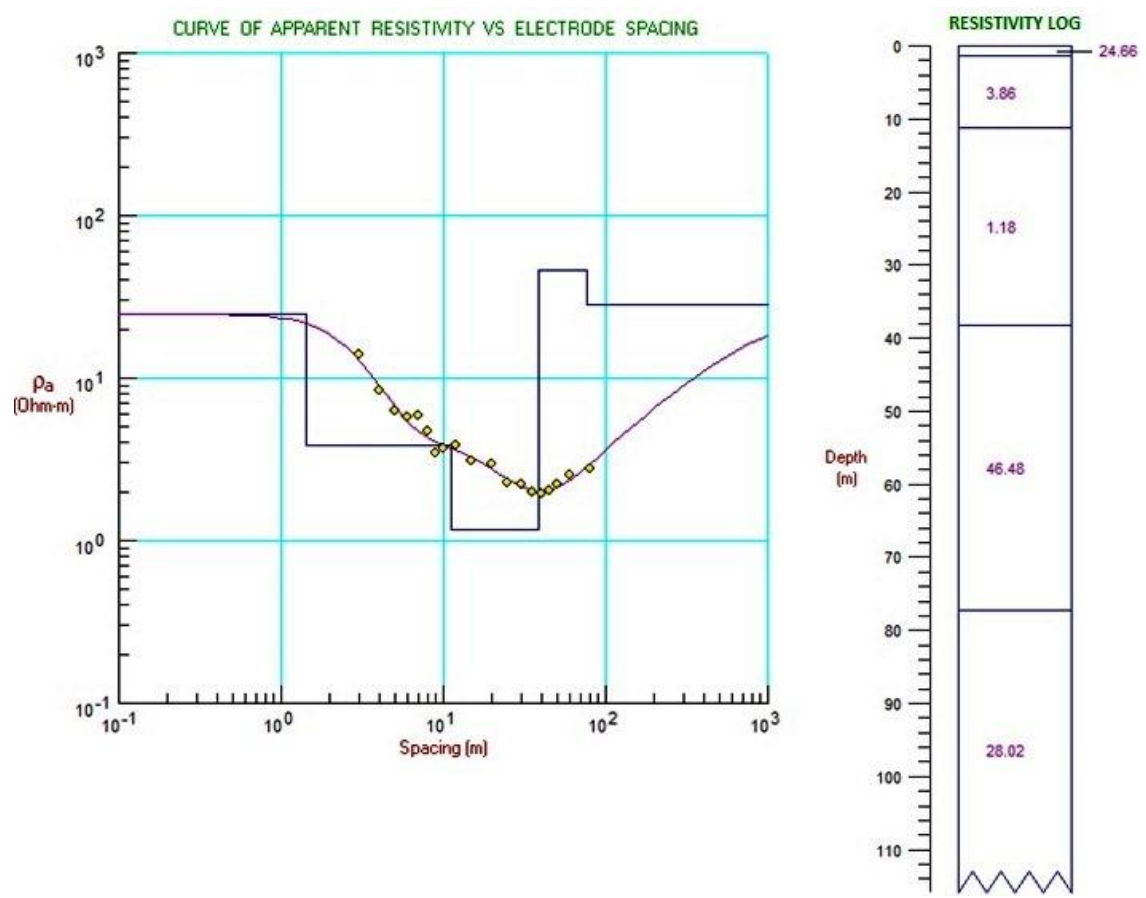

Gambar 7. Kurva dan log resistivitas batuan bawah permukaan hasil pemodelan resistivitas 1D pada titik lokasi Bojongsari 03.

Titik lokasi Bojongsari 03 terletak pada posisi geografis $07^{\circ} 40^{\prime} 13,241^{\prime \prime}$ dan $109^{\circ} 43^{\prime} 35,68^{\prime \prime}$ dengan panjang bentangan elektroda arus (1/2AB) adalah $80 \mathrm{~m}$. Berdasarkan hasil pemodelan seperti Gambar 7, lapisan akuifer air tanah dangkal diinterpretasi tersusun atas pasir berbutir halus $(\rho=1,18 \Omega \mathrm{m}$ ) dengan kedalaman 11,28 - 38,25 $\mathrm{m}$ yang diduga bagian dari formasi Aluvium. Adapun lapisan akuifer air tanah dalam yang prospek tidak ditemukan. Lapisan batuan kelima yang diestimasi terdiri atas perselingan batu pasir dan batu lempung kompak $(\rho=28,02 \Omega \mathrm{m})$ dengan kedalaman 77,25 $\mathrm{m}$ hingga batas bawah yang tidak jelas, yang diperkirakan hanya merupakan lapisan semi akuifer. Lapisan ini diperkirakan merupakan anggota formasi Halang yang terletak di bawah formasi Aluvium. Informasi jenis litologi di bawah lapisan batuan tersebut tidak dapat diakses akibat panjang bentangan elektroda arus pada pengukuran geolistrik terbatas, karena terkendala lembah sungai yang curam. Oleh karena itu berdasarkan nilai resistivitas dan hasil interpretasi litologinya, lapisan 
akuifer dalam di titik lokasi Bojongsari 03 tidak dapat diinterpretasi kedalamannya. ${ }^{10}$ Secara lengkap hasil interpretasi batuan bawah permukaan pada titik lokasi Bojongsari 03 dapat dilihat pada Tabel 3 .

Tabel 3. Interpretasi hasil pemodelan data resistivitas 1D pada titik lokasi Bojongsari 03

\begin{tabular}{ccccc}
\hline \multirow{2}{*}{ No. } & $\begin{array}{c}\text { Log Resisitivitas } \\
\text { ( }\end{array}$ & \multirow{2}{*}{ Kedalaman $(\mathrm{m})$} & \multicolumn{2}{c}{ Hasil Interpretasi } \\
\cline { 4 - 5 } & 24,66 & $0-1,42$ & Lanau pasiran kering & Hidrogeologi \\
2 & 3,86 & $1,42-11,28$ & Lom akuifer \\
3 & 1,18 & $11,28-38,25$ & Pasir berbutir halus & Non akuifer \\
4 & 46,48 & $38,25-77,25$ & $\begin{array}{c}\text { Perselingan batu pasir, } \\
\text { batu lempung, dan tuff }\end{array}$ & Non akuifer \\
& 28,02 & $\geq 77,25$ & $\begin{array}{c}\text { Perselingan batu pasir dan } \\
\text { batu lempung kompak }\end{array}$ & Semi akuifer \\
\hline
\end{tabular}

\section{KESIMPULAN}

Pengukuran geolistrik menggunakan konfigurasi Schlumberger telah dilaksanakan di Desa Bojongsari, Kecamatan Alian, Kabupaten Kebumen sebagai upaya untuk mencari sumber air tanah yang prospek dimanfaatkan untuk Penyediaan Air Minum dan Sanitasi Berbasis Masyarakat (PAMSIMAS). Berdasarkan hasil penelitian diperoleh hasil bahwa lapisan akuifer dalam (deep aquifer) yang diperkirakan prospek digunakan untuk proyek penyediaan air bersih dalam skala besar adalah lapisan akuifer air tanah dalam di titik lokasi Bojongsari 01 dengan posisi $07^{\circ} 40^{\prime}$ 07,637'dan $109^{\circ} 43^{\prime}$ 26,740". Lapisan air tanah dalam tersebut diperkirakan tersusun atas pasir berbutir halus $(\rho=0,44 \Omega \mathrm{m})$ dengan kedalaman 33,72 - 85,76 m dan ketebalan 52,04 m. Lapisan akuifer ini diperkirakan sangat prospek karena kemungkinan volume airnya sangat besar dan bersih.

Lapisan akuifer air tanah dalam untuk titik lokasi Bojongsari 02 dan Bojongsari 03 tidak dapat diinterpretasi dengan baik. Namun untuk lapisan akuifer air tanah dangkal diperkirakan masih dapat dimanfaatkan oleh masyarakat sebagai sumber air bersih melalui sumur. Agar lapisan akuifer air tanah dalam di kedua titik lokasi ini dapat diinterpretasi dengan baik, maka perlu disediakan lokasi bentangan elektroda arus yang panjang pada pengukuran geolistrik dengan konfigurasi Schlumberger. Namun demikian apabila masih terdapat kendala, maka disarankan menggunakan metode geofisika yang lain yang tidak tergantung dari bentangan elektroda seperti metode gravitasi dan magnetik.

\section{UCAPAN TERIMA KASIH}

Ucapan terima kasih disampaikan kepada Kepala Desa Bojongsari, Kecamatan Alian Kabupaten Kebumen atas ijin dan kepercayaannya kepada tim Survei Geolistrik UNSOED. Terima kasih juga disampaikan kepada Kepala Laboratorium Elektronika, Instrumentasi, dan Geofisika Fakultas MIPA Universitas Jenderal Soedirman atas fasilitas alat geolistrik Resistivity meter merk NANIURA dan kelengkapan survei lainnya yang disediakan. Dan terima kasih juga disampaikan kepada Bapak Handoko dan seluruh tim PAMSIMAS atas bantuan dana, konsumsi, dan akomodasi yang disediakan dalam kegiatan penelitian ini. 


\section{DAFTAR PUSTAKA}

1. PAMSIMAS (Penyediaan Air Minum dan Sanitasi Berbasis Masyarakat): Asosiasi BPSPAMS; [Internet]. 2013 [Disitasi 5 Januari 2016]. Diakses dari laman:http://new.pamsimas.org/index.php?

2. Kekeringan makin parah, BPBD layani hingga larut malam. Kebumen Ekspres [Online]. 2015 November 28 [Disitasi 6 Januari 2016]. Diakses dari laman:http://www.kebumenekspres.com/2015/10/kekeringan-makin-parah-bpbdlayani.html

3. Telford WM, Gedaart LP, Sheriff RE. Applied geophysics. New York: Cambridge University Press; 1990.

4. Sehah, Hartono. Kajian potensi sumber air tanah untuk irigasi di kawasan cekungan air tanah Purwokerto-Purbalingga berdasarkan resistivitas batuan bawah permukaan. Jurnal Pembangunan Pedesaan (JPP). Juni 2010;10(1):23-32

5. Sehah, Hartono. Investigasi karakteristik akuifer air tanah di kawasan lahan kritis daerah aliran sungai serayu desa wlahar, kecamatan adipala, kabupaten cilacap. Prosiding Seminar Nasional Fisika (SNF) Tahun 2011 Universitas Negeri Semarang; 8 Oktober 2011; Semarang, Indonesia.

6. Milsom J. Field geophysics; the geological field guide series. Third Edition.West Sussex, England: John Wiley and Sons Ltd;2003.

7. Mariita N O. Schlumberger vertical soundings; techniques and interpretations with examples from krisuvik and glerardalur, iceland and olkarta, kenya. Nairobi: UNU Geothermal Training Programme, National Energy Authority;1986.

8. Herman R. An introduction to electrical resistivity in geophysics. American Journal of Physics. September 2001;69(9):943-952.

9. Asikin S, Handoyo A, Busono H, Gafoer S. Peta geologi lembar Kebumen, Jawa. Bandung: Pusat Penelitian dan Pengembangan Geologi (P3G);1992.

10. Sehah, Hartono, Setiaji. Pengukuran geolistrik tahanan jenis dengan teknik vertikal sounding untuk mengidentifikasi kedalaman akuifer air tanah yang prospek untuk dieksplorasi. Jurnal FLUX. Juli 2010;04(02): 134-142. 